\title{
KEMAMPUAN DAYA DUKUNG LINGKUNGAN FISIK DAN PENGARUHNYA TERHADAP KEPUASAN WISATAWAN DI AGROWISATA GREEN HOUSE LEZATTA KABUPATEN AGAM PROVINSI SUMATERA BARAT
}

\author{
WINA ASTY 1 , DWI PRATITIWI WULANDARI ${ }^{2}$, DEWI ANGGRAINI ${ }^{3}$ \\ Universitas Muhamadiyah Sumatera Barat ${ }^{1,3}$, Univeristas Negari Padang ${ }^{2}$ \\ astywina83@gmail.com ${ }^{1}$,dwiktiwi@gmail.com ${ }^{2}$
}

\begin{abstract}
Agro-tourism Green House Lezatta in Agam Regency is known as flower gardens and dollhouses attractions. Based on the observations, tourist attraction has $765 \mathrm{~m} 2$, tourist visit rate 600 to 1000 people in the high season, and 500 to 600 people in the low season. The purpose of this study was to determine capacity capability in the physical environment of the Green House Lezatta, whether the quality of the physical environment of a tourist attraction can affect the satisfaction and comfort of tourists visiting. The method used is descriptive quantitative, to assess the maximum capacity of the Green House Lezatta tourist attraction, used the Cifuentes Physical Carrying Capacity (PCC) method. Data obtained through distributing questionnaires to 91 respondents, with the sampling technique using random sampling. The results found carrying capacity of Green House Lezatta's physical environment was not following the standards of a tourist attraction because the number of tourists visiting had exceeded the existing land capacity. In the satisfaction variable, the results showed $49.5 \%$ of tourists said not satisfied with the condition of tourist attraction because the atmosphere was uncomfortable and narrow. Recommend to conduct the review of the design of a tourist site following tourism standards for future development.
\end{abstract}

Keyword: Physical Carrying Capacity, Tourist Satisfaction

Abstrak: Agrowisata Green House Lezatta di Kabupaten Agam dikenal dengan taman bunga dan rumah boneka aneka warna sebagai daya tariknya. Berdasarkan hasil observasi didapatkan bahwa objek wisata tersebut memiliki luas $765 \mathrm{~m}^{2}$, dengan tingkat kunjungan wisatawan sebesar 600 sampai 1000 orang saat high season, dan 500 sampai 600 orang saat low season. Tujuan penelitian ini untuk mengetahui kemampuan kapasitas maksimum pada lingkungan fisik objek wisata Green House Lezatta, apakah kualitas lingkungan fisik sebuah objek wisata dapat mempengaruhi kepuasan dan kenyamanan wisatawan yang berkunjung. Metode yang digunakan dalam penelitian ini adalah kuantitatif deskriptif, dan untuk mengkaji jumlah maksimal daya tampung objek wisata Green House Lezatta digunakan metode tambahan yaitu Physical Carrying Capacity (PCC) Cifuentes. Data diperoleh melalui penyebaran angket kepada 91 orang responden, dengan teknik sampel menggunakan random sampling. Hasil penelitian menemukan bahwa daya dukung lingkungan fisik Green House Lezatta tidak sesuai dengan standar sebuah objek wisata, karena jumlah wisatawan yang berkunjung perhari sudah melebihi kapasitas lahan yang ada. Kemudian pada variabel kepuasan didapatkan hasil bahwa 49,5\% wisatawan yang berkunjung menyatakan tidak puas dengan kondisi objek wisata tersebut, karena suasana wisata tidak nyaman dan sempit. Disarankan untuk melakukan kajian ulang dalam perancangan tapak wisata yang sesuai dengan standar kepariwisataan untuk pengembangan kedepannya.

Kata Kunci: Daya Dukung Lingkungan Fisik, Kepuasan wisatawan 
Vol. 2 No.2 Juni 2020

\section{A. Pendahuluan}

Sumatera Barat adalah salah satu Provinsi di Indonesia yang memiliki kekayaan alam dan budaya yang berpotensi menjadi destinasi wisata unggulan. Salah satu destinasi potensial tersebut adalah Kabupaten Agam, daerah ini dikenal memiliki wisata budaya dan alam yang terbentang indah dari pesisir pantai hingga ke puncak gunung. Beberapa objek wisata yang terdapat di Kabupaten yang memilki Ibu Kota bernama Lubuk Basung ini antara lain Pantai Bandar Mutiara, Pantai Tiku, Objek wisata Muko-Muko, Air Tigo Raso, Bunga Raflesia, Ambun Pagi, Puncak Lawang, Air Terjun Gadih Ranti, Danau Maninjau, Tarusan Kamang, Janjang Koto Gadang, Ambun Tanai, dan Ngalau Kamang. Potensi wisata budaya dan sejarah yang ada di Kabupaten Agam antara lain Makan Tuanku Nan Rentjeh, Mesjid Kuno Mingkudu, Museum Rumah Kelahiran Buya Hamka, dan Monumen pesawat Avro Anson Republik Indonesia 003. Kemudian objek wisata buatan yang cukup terkenal di Kabupaten Agam antara lain Kelok 44 dan Green House Lezatta.

Green House Lezatta merupakan objek wisata buatan baru yang berkonsep agrowisata dengan mengusung pembibitan beragam jenis bunga sebagai diferensiasinya. Objek wisata yang terletak di Desa Koto Hilalang, Baso, Kecamatan Ampek Angkek Canduang ini memiliki lokasi yang tidak terlalu luas yaitu lebih kurang 765 meter persegi, sehingga memerlukan strategi yang inovatif dan kreatif untuk mengembangkan area yang cukup sempit tersebut agar dapat memenuhi kebutuhan wisatawan. Pada awalnya Green House Lezatta hanyalah diperuntukkan untuk agrowisata pembibitan bunga, namun seiring perjalanannya kemudian berkembang berbagai atraksi unik. Beberapa atraksi yang disuguhkan objek wisata ini antara lain rumah boneka warna warni dengan jenis desain berbeda seperti rumah hobbit dan rumah berbi. Ukuran rumah-rumah boneka ini tidak cukup besar, hanya dapat memuat maksimal 5 (lima) orang saja. Selain beraneka ragam taman bunga dan rumah boneka, Green House Lezatta juga memiliki beberapa fasilitas penunjang wisata lainnya seperti café, galeri, dan penyewaan kostum yang sesuai dengan konsep wisatanya.

Konsep wisata seperti ini memang sedang marak dibeberapa daerah di Indonesia, namun di Sumatera Barat terutama Kabupaten Agam, atraksi ini tergolong baru, sehingga hal tersebut sangat menarik minat wisatawan untuk berkunjung. Hingga kemudian kaum milenial dan masyarakat yang memiliki antusiasme tinggi pada fotografi dan media sosial beramai-ramai berwisata ke Green House Lezatta. Berdasarkan data yang didapatkan dari pihak manajeman Green House Lezatta, saat musim liburan (high season) jumlah wisatawan yang berkunjung ke objek wisata ini rata-rata 1000 orang perhari, dan pada low season rata-rata 500 hingga 600 orang perhari dalam durasi waktu operasional dari pukul 09.00 pagi sampai pukul 18.00 Waktu Indonesia Barat, pernyataan tersebut dapat ditampilkan pada tabel 1 berikut:

Tabel 1 Tingkat Kunjungan Wisatawan Ke Green House Lazatta Tahun 2017

\begin{tabular}{ll}
\hline Musim & Jumlah Kunjungan/Hari (orang) \\
\hline Peak/High Season & $>601-1000$ \\
Low Season & $500-600$ \\
\hline
\end{tabular}

Sumber: Manajemen Green House Lezatta, 2018

Meningkatnya kunjungan wisatawan dari waktu ke waktu tentunya juga menjadi salah satu tantangan yang bisa mendatangkan masalah bagi pihak pengelola, karena 
luas area wisata yang melebihi kapasitas dapat menyebabkan ketidaknyamanan pada wisatawan. Berbagai keluhan wisatawan seperti suasana yang sempit dan panas, tidak terkendalinya kebersihan dibeberapa fasilitas, dan tidak tersedianya area parkir karena sudah melebihi daya tampung. Keadaan ini tentunya tidak boleh terus terjadi, karena rasa tidak nyaman pada wisatawan akan berubah menjadi ketidakpuasan, sehingga akan berpengaruh pada loyalitas dan niat wisatawan untuk berkunjung kembali pada objek wisata tersebut. Kepuasan adalah suatu perasaan senang yang dapat dirasakan seseorang yang muncul akibat kinerja suatu produk yang dipersepsikannya sudah sesuai dengan ekspektasi. Kepuasan wisatawan juga dapat dikatakan sebagai sebuah ukuran keseluruhan yang berdasarkan pada pendapat wisatawan tersebut pada kualitas suatu destinasi. Ukuran ini bisa dipertimbangkan sebagai sebuah nilai terhadap hasil dan kualitas dari sebuah destinasi wisata, misalnya pelayanan dan perlakuan yang dirasakan wisatawan saat mengunjungi destinasi. Kepuasan biasanya dapat diukur dengan tiga pertimbangan yaitu, senang atau tidak seorang wisatawan setelah memutuskan berkunjung kesebuah destinasi, kedua, kepercaan bahwa tindakan memilih destinasi tersebut adalah hal yang benar, dan terakhir, tingkat kepuasan wisatawan secara keseluruhan terhadap destinasi yang dikunjungi (Kotler dan Keller, 2008; Prayag, 2008 dalam Coban, 2012; Yuksel et al., 2010; dalam Hanif et al., 2016).

Berdasarkan teori tersebut, bisa ditegaskankan lebih lanjut bahwa daya dukung fisik atau lingkungan sebuah objek wisata dapat mempengaruhi tingkat kepuasan wisatawan. Menurut UU 32/2009, Tentang Pengelolaan Lingkungan Hidup, daya dukung lingkungan adalah kemampuan suatu lingkungan hidup dalam mendukung perikehidupan setiap manusia dan semua mahkluk hidup lainnya. Daya dukung suatu kawasan wisata juga termasuk daya dukung biogeofisik serta sosial ekonomi dan budaya dari suatu tapak atau lokasi wisata untuk menunjang aktifitas kepariwisataan didalamnya tanpa menyebabkan kemerosotan pada stabilitas ekologi atau lingkungan hidup, dan disisi lain tetap dapat memberi kepuasan kepada wisatawan saat menikmati tapak wisata tersebut (Siswantoro, 2012 dalam Ariaharvi, 2017). Pendapat senada juga dinyatakan oleh Libosada (1998) dalam Nurhidayah (2017), bahwa daya dukung suatu kawasan wisata adalah kemampuan suatu wilayah menampung sejumlah orang untuk berwisata tanpa menyebabkan kerusakan pada lokasi tersebut dengan tidak mengurangi kepuasan pengunjung.

Jumlah wisatawan yang melampaui batas dapat berpotensi merusak lingkungan, oleh sebab itu diperlukan pengendalian resiko dengan penerapan pariwisata yang bertanggung jawab. Daya dukung fisik atau physical carrying capacity adalah batas maksimal wisatawan yang berkunjung kesuatu kawasan wisata dalam satu hari, yang didapat berdasarkan perhitungan rumus PCC (Physical Carrying Capacity), sehingga diketahui seberapa besar daya dukung atau kemampuan sebuah kawasan wisata dapat menampung wisatawan, apakah jumlah wisatawan yang diterima perhari sudah melampaui batas normal atau masih bisa ditingkatkan. Berdasarkan temuan masalah tersebut maka peneliti melakukan observasi lebih dalam untuk mengkaji objek wisata Green House Lezatta dengan menggunakan metode Physical Carrying Capacity (PCC) yang dikembangkan oleh Cifuentes.

\section{B. Metodologi Penelitian}

Penelitian ini adalah penelitian kuantitatif dengan pendekatan deskriptif, dimana objek yang diteliti akan dideskripsikan sesuai data atau sampel yang telah didapatkan dilapangan sebagaimana adanya tanpa digeneralisasi. Teknik pengambilan sampel yang digunakan adalah random sampling, yaitu mengambil sampel yang representatif E-ISSN: 2657-0300 Lembaga Penelitian dan Penerbitan Hasil Penelitian Ensiklopedia 229 
dari sebuah populasi yang telah ditentukan dan dilakukan dengan cara acak (Sugiyono, 2015). Jumlah sampel pada penelitian ini adalah 91 orang yang terdiri dari wisatawan yang berkunjung ke Green House Lezatta.

\section{Hasil dan Pembahasan}

\section{Hasil Analisis Physical Carrying Capacity (PCC) Green House Lezatta}

Sesuai data pada tabel 1 didapatkan angka rerata kunjungan wisatawan setiap harinya pada tahun 2018 adalah 601 orang hingga 1000 orang pada hari Sabtu dan Minggu atau saat high season, dan 500 hingga 600 orang pada hari biasa atau low season. Data ini didapatkan dari hasil observasi peneliti dengan pihak manajemen atau pengeloloa objek wisata Green House Lezatta.

Berdasarkan data tersebut, untuk mengetahui tingkat PCC Green House Lezatta maka dilakukan olah data menggunakan rumus Cifuentes (1992) dalam Kholiq et al (2018), sebagai berikut:

\section{$\mathbf{P C C}=\mathbf{A} \times \frac{1}{B} \times \mathbf{R f}$}

Keterangan:

$\mathrm{PCC}=\quad$ Physical Carrying Capacity

$\mathrm{A} \quad=\quad$ Luas area wisata

$\frac{1}{\mathrm{~B}} \quad=$ Luas area yang diperlukan seorang wisatawan saat berwisata agar tetap merasa nyaman dan puas, untuk hal ini maka digunakan nilai hitung yang ditetapkan oleh Douglas (1975) dan Fandeli (2009) dalam Kholiq et al (2018), yaitu $65 \mathrm{~m}^{2}=0,0065$ ha.

Rf $=$ Faktor Rotasi/pergantian orang dalam kegiatan wisata, dalam hal ini ditetapkan 2 (dua) jam, sesuai standar yang terdapat dalam rumus.

Dengan menggunakan rumus tersebut maka didapatkan hasil PCC Green House Lezatta sebagai berikut:

$$
\begin{aligned}
\text { PCC } & =765 \times \frac{1 \times 2}{65} \\
& =23.5384 \\
& =24 \text { (dibulatkan) }
\end{aligned}
$$

Sesuai hasil perhitungan diatas maka didapatkan angka 24, artinya adalah dengan luas lokasi Green House Lezatta yaitu $765 \mathrm{~m}^{2}$, maka secara ideal hanya dapat menampung wisatawan sebanyak 24 orang dalam waktu 2 (dua) jam, artinya Green House Lezatta harus melakukan rotasi atau pergantian wisatawan secara berkesinambungan setiap 2 (dua) jam sekali agar wisatawan memiliki cukup ruang yang nyaman untuk berwisata dan tidak menyebabkan kerusakan lingkungan.

\section{Hasil Analisis Kepuasan Wisatawan}

Berdasarkan analisis data dari angket yang disebarkan kepada wisatawan yang berkunjung ke Green House Lezatta, maka didapatkan hasil yang dijabarkan pada tabel 1 berikut: 
Tabel 1. Persentase Kepuasan Wisatawan Green House Lezatta

\begin{tabular}{lll}
\hline Tingkat Kepuasan & Jumlah Responden & Persentase \\
\hline Sangat Tidak Puas & 0 & $0 \%$ \\
Tidak Puas & 45 & $49,5 \%$ \\
Cukup Puas & 25 & $27,5 \%$ \\
Puas & 21 & $23 \%$ \\
Sangat Puas & 0 & $0 \%$ \\
\hline Total responden & 91 & $100 \%$ \\
\hline
\end{tabular}

Sumber: Hasil Analisis, 2018

Dari tabel 1 dapat dijelaskan bahwa total responden adalah 91 orang wisatawan, dan $49,5 \%$ responden atau 45 orang wisatawan menyatakan tidak puas dengan kondisi objek wisata Green House Lezatta, 27,5\% responden atau 25 orang wisatawan menjawab cukup puas, kemudian $23 \%$ responden atau 21 orang wisatawan merasa sudah puas, namun tidak ada responden yang menyatakan sangat puas ataupun sangat tidak puas saat berkunjung ke objek wisata tersebut.

\section{Pembahasan}

Hasil analisis data menunjukkan bahwa physical carrying capacity (PCC) objek wisata Green House Lezatta tidak sesuai dengan standar minimal daya dukung fisik pada sebuah objek wisata, karena jumlah wisatawan yang berkunjung perhari pada hari biasa adalah 500-600 orang dan 601-1000 orang pada high season, sedangkan jumlah ideal yang seharusnya adalah 24 orang setiap 2 (dua) jam, atau jumlah maksimal wisatawan yang dapat ditampung dalam durasi waktu operasional dari pukul 09.00 pagi sampai pukul 18.00 sore adalah 108 orang wisatawan, sehingga dapat ditegaskan bahwa wisatawan yang berkunjung sudah melebihi kapasitas lahan yang ada. Kelebihan kapasitas wisatawan ini tentu saja menyebabkan suasana wisata menjadi tidak nyaman karena wisatawan harus saling berdesak-desakan satu sama lain. Hal itu terbukti dari hasil penelitian yang menunjukkan bahwa sebagian besar wisatawan yaitu 49,5\% responden merasa tidak puas berwisata ke Green House Lezatta.

Tujuan wisata adalah untuk memberi rasa senang pada pelakunya, namun jika objek wisata tersebut tidak sesuai dengan aturan yang ada, maka rasa senang akan berubah menjadi rasa tidak puas karena wisatawan tidak dapat menikmati kegiatan wisata tersebut. Hal ini tentunya akan berpengaruh buruk pada citra objek wisata Green House Lezatta kedepannya, karena dapat mempengaruhi minat wisatawan untuk tidak melakukan kunjungan kembali.

\section{Penutup}

Berdasarkan temuan dan hasil analisis penelitian pada objek wisata Green House Lezatta, maka beberapa hal yang dapat disimpulkan adalah sebagai berikut: Objek wisata Green House Lezatta adalah sebuah destinasi wisata baru yang mengusung konsep agrowisata dengan mengakat tema taman bunga sebagai diferensiasinya. Hasil analisis menemukan bahwa jumlah rata-rata wisatawan yang berkunjung ke objek wisata Green House Lezatta tidak sesuai dengan standar maksimal daya dukung fisik atau kapasitas lahan. Dengan luan $765 \mathrm{~m}^{2}$, objek wisata Green House Lezatta seharusnya hanya bisa menampung 108 orang wisatawan perhari, atau 24 orang wisatawan yang dirotasi per 2 (dua) jam. Sebagian besar wisatawan atau 49,5\% responden yang berkunjung ke objek wisata Green House Lezatta merasa tidak puas 
Vol. 2 No.2 Juni 2020

dengan situasi dan kondisi di objek wisata tersebut, karena belum sesuai dengan ekpsektasi.

\section{Daftar Pustaka}

Ariaharvi, Lalu Razieb. 2017. Analisis Daya Dukung Lingkungan Pariwisata Kawasan Hutan Lindung Sekaroh Kabupaten Lombok Timur. Sarjana thesis, Universitas Brawijaya.

Hanif, Asya., Kusumawati, Andriani., Mawardi, M. Kholid. 2016. Pengaruh Citra Destinasi Terhadap Kepuasan Wisatawan Serta Dampaknya Terhadap Loyalitas Wisatawan (Studi Pada Wisatawan Nusantara Yang Berkunjung Ke Kota Batu). Jurnal Administrasi Bisnis, Vol. 23. Universitas Brawijaya.

Kholiq, Muhammad Wahda Abdul et al. 2018. Kajian Kapasitas Kunjungan Optimum Wisata Alam Kota Batu, Provinsi Jawa Timur Menggunakan Metode Carrying Capacity. Skripsi Thesis, Institut Teknologi Nasional Malang.

Sugiyono (2015). Metode Penelitian Kombinasi (Mix Methods). Bandung: Alfabeta.

Nurhidayah, Anas. 2017. Kajian Kesesuaian Dan Daya Dukung Kawasan Ekowisata Pantai Dan Terumbu Karang Berbasis Masyarakat Di pantai Bangsring Banyuwangi, Jawa Timur. Skripsi Thesis, Institut Teknologi Nasional Malang.

Wulandari, Dwi Pratiwi, et al. "Coronavirus Tourism: Charming Voyagers in Time of Novel Coronavirus." International Journal of Advanced Science and Technology 29.06 (2020): 1708-13. 